\title{
Exploring and Enhancing School Leader Preparation: Using Communications Technology With Online Educational Leadership Internship Programs
}

\author{
Leonard J. Clark \\ University of Louisiana at Monroe, Monroe, USA \\ Thillainatarajan Sivakumaran, Holly K. Hall \\ Arkansas State University, Jonesboro, USA \\ Brooke O. Keels \\ University of Louisiana at Monroe, Monroe, USA
}

\begin{abstract}
The researchers reviewed best practices school leaders should have and explored the effective use of communications technology to supervise interns in their final semester of internship. The study is a comparison of what interns reported as effectiveness in their preparation, performance level, and overall perceived supervisor support. Other data related to level of confidence in their preparation, experiences, and activities were collected from interns using a 12-question survey. Conclusions drawn from this small study seemed to indicate that interns can feel supported in the internship experience when the quality of the experience was preserved regardless to whether they received supervision electronically or via face-to-face visits.
\end{abstract}

Keywords: communications technology, internship, online programs, distance site visit, video calling

\section{Introduction and Literature Review}

\section{Leadership}

Terry (1960) (as cited in Hersey \& Blanchard, 1982) offered a rather simple definition adequate for the purpose of this study; he defined leadership as the activity of influencing people to strive willingly for group objectives. Also cited in Hersey and Blanchard (1982), Koontz and O'Donnell (1972) defined leadership as influencing people to follow in the achievement of a common goal. Relevant today are these simple defining ideas of leadership although the context of leading is yet more complex than when the authors conceived their definitions. Northhouse (2013) posited that there are many definitions of leadership and described an evolution of the concept of leadership with often little consensus. He summarized this evolution by asserting that leadership was indeed the influence of an individual on a group to achieve an objective as aforementioned. He described four components that are crucial to conceptualizing leadership clearly: (a) ability to influence — where leaders are apt to affect followers and their actions and decisions; (b) leadership as process-where leadership moves

Leonard J. Clark, Ed.D., associate professor, Director of Graduate School, University of Louisiana at Monroe.

Thillainatarajan Sivakumaran, associate professor, Executive Director of Global Initiative, Arkansas State University.

Holly K. Hall, associate professor, Department of Journalism, Arkansas State University.

Brooke O. Keels, assistant professor, College of Arts, Education and Sciences, University of Louisiana at Monroe. 
between followers and the one appointed to lead interacting and one being affected by the other; (c) leadership interaction in groups - where a group of followers are affected by the leader for a determined purpose; and (d) common goals of leadership - where attention is given to the leader's direction for the followers in achieving a common objective or aim. Green (2013) proposed a general concept of leadership as a "process used by leaders to give purpose to the collective efforts of members of the organization while influencing them to work collaboratively in an environment of mutual respect and trust" (p. 26).

Transitioning from a general definition of leadership and common components as Northhouse (2013) asserted, it is incumbent upon the notion of leadership to explore how the concepts square with instructional leadership. Hoy and Miskel (2013) offered a simple understanding of the daily complexity of instructional leadership. They submitted that the intent of instructional leadership should be to focus on improving teaching and learning. Specifically, instructional leadership effectiveness or ineffectiveness is evidenced in a leader's ability to influence curricular content, teaching and assessment strategies, and cultural norms. Additionally, it should not be assumed or expected this instructional leadership can only originate from the principal, but can come from other administrators in the school setting, community leaders, and parents. The focus of this review, however, relies on the principal as the administrator primarily responsible for leadership in schools. Hoy and Miskel (2013) cited the research by Kyung Ae Chung and Cecil Miskel (1989) in which they summarized that the nature of administrative work that still holds true today regardless of administrative culture and location. The administrative work can be described as grueling work that taxes the administrator emotionally and physically due to the pace, challenging circumstances, and sometimes unpredictable nature of administrative events. New reforms and demands relative to achievement standards coupled with the fluidity of new technology garnered still more demand on the administrator or instructional leader. As new administrative demands have emerged, the curriculum, context, and means by which new educational leaders are prepared have had to change also to meet the new challenges, licensure requirements, and demands. As a result, federal and state education accountability groups have imposed scrutiny and rigorous evaluation of mechanisms used to assess leadership preparation programs (Orr, 2011). The Interstate School Leaders Licensure Consortium (ISLLC) Standards developed by the Council of Chief State School Officers provide the assessment content for the required School Leadership Licensure Assessment (SLLA). Louisiana with 12 other states uses the SLLA as the primary means to license educational leaders (Cordeiro \& Cunningham, 2013). The ISLLC Standards provide the foundation by assignments are developed and provide the context for discussion for supervisor and intern training. The current standards begin with the same stem and can be summarized in the following from Cordeiro and Cunnigham (2013). A school administrator is an educational leader who promotes the success of all students by:

Standard 1-Facilitating the development, articulation, implementation, and stewardship of a vision of learning that is shared and supported by the school community;

Standard 2-Advocating, nurturing, and sustaining a school culture and an instructional program conducive to student learning and staff professional growth;

Standard 3-Ensuring management of the organization, operations, and resources for a safe, efficient, and effective learning environment;

Standard 4-Collaborating with families and community members, responding to diverse community interests and needs, and mobilizing resources;

Standard 5-Acting with integrity, with fairness, and in an ethical manner; 
Standard 6-Understanding, responding to, and influencing the larger political, social, economic, legal, and cultural context.

These standards are reasonable expectations of every school leader; however, just as a beginning teacher deserved mentoring, novice school leaders need coaching to reach the expectations of the standards. With a focus on coaching that led to effective leadership, Bambrick-Santoyo (2013) asserted that the important question how we can help leaders build their skills must be the approach toward good leadership. He proposed that a distinction be made between what he called fixed and growth mindsets and the typical feedback often given to emerging leaders. In this approach, he suggested smaller pieces of feedback or strategies then looked for evidence in actions. The coach illustrated or modeled the strategy rather than simply telling the leader to implement the strategy. Bambrick-Santoyo (2013) further purported that from coaching, practice became essential for the success of the learned strategy and transformation of the leader.

\section{Leadership and School Success}

Siccone (2012) asserted that there are essential skills every educational leader must possess to bring about the reform that precipitates efficacy. These essential skills are grounded in the notion that for schools to succeed, there must be continuous improvement. Continuous improvement embraces the management of change. Siccone (2012) offered steps for which educational leaders must engage to navigate and manage change or reform. He shared six steps to manage such a structure. In his first step, he described a concept of promoting a shared leadership culture within a school setting through a nurtured structure. He offered that the long held notion that a leader is a sort of hero is not one that can continue with any success, instead, supports strategies allowing the weight of leadership to permeate throughout the school. Secondly, a school leader must have firmly established a vision for school success. Envisioning a mission for school success allows a school leader to create a culture of successful organizational direction forward. In Siccone's third step, he advocated that an educational leader cannot just rely on possessing a mission, but the leader must have firmly in mind a plan for success he can communicate as the clear path to manifestation of the vision. Finally, an educational leader clarifies that school reform plans are aligned with the vision and ultimately toward improving student performance (Siccone, 2012). In the fourth step, the authors cautioned that even with the first steps firmly in place, progress can be yet hindered if there is no allowance for resource allocation to support school reform initiatives. He emphasized the need to evaluate the use of resources in relation to the expectation of results for students. Developing capacity for school success is Siccone's fifth step. This step is critical because it involves relevant training and coaching of the school's faculty and staff. In this step, however, the authors raised the expectation by also recommending evaluation of professional development and identifying strategies to address weaknesses. Too often professional development is engaged to meet the mandate, but as Siccone pointed out here, the professional development is not adequately evaluated to determine effectiveness for continuing school success. Siccone's final step to managing change is measuring and rewarding school success. With this final step, the authors reminded readers that change management requires taking stock of the ones who have a stake in the school's success. It matters not if all the previous steps are in place, stated Siccone if there is no method to determine that success has been realized and no reward for achieving the success. The authors purposed that this final step is important and will assess the school's dimension for or aversion toward change.

\section{Communications Technology}

Most would agree that communication and learning technology has had a significant impact on how teachers 
teach and prepare college students. Faculty at colleges and universities are increasingly utilizing technology in their classrooms. From "smart" classrooms to Apple TV to social media, technology is used to augment, and in some respect, replace traditional teaching techniques. In an internship setting, technology can bridge the communication gap between student and supervisor, but is using this technology as effective in the quality of preparation as traditional face-to-face classroom interactions?

Therefore, it becomes incumbent on all educational leadership programs to provide a segway that will allow sustaining quality in preparation. Internships, then is a proven method to prepare students for the professional world of work, and they allow universities to maintain open networks and affiliations with organizations, facilitating an exchange of information on current practices, trends, and recommendations. An effective internship experience is one that would "encourage contact between faculty and students as well as develop... Students are exposed to numerous active learning techniques and receive prompt, ongoing feedback about their performance" (Implementing and Assessing Internships, 2002, p. 67). These active learning experiences allow students to apply the theories and principles of teaching in real classroom simulation. Therefore, the quality of supervision of internships is critical. Supervisors assess the intern's performance, mentor the student through difficult situations, provide emotional support, set forth prescribed activities and assist students in reflecting on those activities, and keep the students on task.

Providing feedback and support to students face-to-face can be difficult due to time, cost, or geographical limitations. One of the potential solutions to this issue is the use of technology to facilitate communication and learning during the internship process. Computer-assisted instruction (CAI) is increasingly popular in internship/practicum experiences. This instructional method can be synchronous using Web-based tools that allow for discussion and communication in real time, such as video conferencing. CAI can also be asynchronous allowing for communication to occur regardless of time constraints, such as communication via e-mail, blogs, and discussion boards.

For universities who send students to rural areas, CAI offers the promise of enabling a rich internship experience by maintaining a connection with the internship supervisor who cannot travel to the internship site frequently. The results of one study in Australia revealed that using CAI for an internship experience where many of the students were in isolated areas, created an engaged, supportive environment with opportunities to discuss urgent issues in a timelier manner than waiting for a site visit from their supervisor (Mayer, 2002).

Increasingly more institutions are exploring opportunities specifically using real-time communication methods to meet with their students experiencing internships. Video conferencing, in particular, holds promise as it allows viewers to note body language and tone of voice. Panos (2005) analyzed video conferencing with students placed internationally in a social work field practicum. Almost $82 \%$ of the respondents reported a remarkable drop in their sense of isolation due to the video conferencing which allowed the students to see their supervisor and other students. Other positive side-effects of video conferencing included increased communication with the placement agency and increased capacity to deal with problem students.

Skype allows users to "have a spoken conversation with (someone) over the Internet" using their software application, "frequently also viewing by Webcam" (Skype, 2013). Adams (2011) defined effective communication as "the interpretation of verbal and nonverbal cues". In her study of using Skype in a radiation therapy clinical situation, Adams found nonverbal cues from students on Skype helpful in determining a student's feelings about a rotation they were experiencing, which then prompted follow-up questions from the supervisor to determine whether issues needed to be resolved. Conclusions from the study illustrate that six out of the seven 
participating students found Skype to be helpful in fostering communication between them and their supervisors. Due to the success of those experiences, the university engaged in the study plans to use video conferencing/Skype in additional programs. In fact, Quillen (2011) asserted that there was no challenge of educators actually recognizing Skype for its potential in instruction. He further asserted that the potential use can be endless depending upon just how far the educators can imagine. Skype can bring enormous benefits for conducting research and engaging in problem-solving opportunities. Additionally, Parker, Boarse-Jelinek, and Herrington (2011) found that student participants in their study used Skype for discussion forums, not for chatting but for assignment planning and social networking. Their study found that use of Skype allowed for in-depth reflection and responding to questions. In that sense, Skype communication made an impact on the quality of student engagement with course content.

While there have been success stories in using CAI to facilitate learning in an internship experience, there are also potential limitations. There may be hardware or software issues, such as poor or inconsistent connection to technology in certain areas, contacting the supervisor unpredictable. There may also be a wide range in the computer/technology skill level of both the students and faculty.

In light of the preceding information, the researchers sought to explore, determine, and assess the effectiveness of electronic technology to supervise educational leadership interns in Louisiana and compare what interns report as effective electronic technology in view of their expected level of performance and overall support. The significance of the project strategies used in the project might positively impact the cost of supervising interns in other programs where an internship is required.

\section{Educational Leadership Internship Course Design}

The internship highlighted in this study enabled candidates to emerge as educational leaders ready to take on the fluid responsibilities inherent in school leadership. Candidates are expected to:

1. Assist school administrators with the development of school action plans;

2. Develop and participate in activities to improve school community relations;

3. Assist with curriculum planning and development;

4. Participate in teacher observation/evaluation;

5. Observe and critique school personnel services and personnel administration;

6. Analyze physical plant and facilities for needed improvements;

7. Participate in fiscal planning and management;

8. Assess school programs related to diversity and service to all students;

9. Assist with the development and implementation of professional development activities;

10. Critique the school's accountability and improvement plans;

11. Use available technology designed to manage school operations effectively;

12. Conduct action research in the assigned schools;

13. Assist with the schools' reports, grants, and records;

14. Critique Bulletin 741.

\section{Research Questions}

This research is guided by the following two research questions:

1. Is there a difference between how the interns perceived their level of performance and preparation when 
the supervisor made an on-site visit and when the supervisor used communications technology in lieu of an on-site visit?

2. Is there a difference between how the interns perceived support from the university supervisor when the supervisor made an on-site visit and when the supervisor used communications technology in lieu of the on-site visit?

\section{Methods and Theoretical Framework}

The plan for the project most closely aligned with a qualitative approach. The sample population included students who previously took Educational Leadership Internship I and were taking the second half of that internship. University supervisors employed at the University of Louisiana at Monroe (ULM) visit each intern regardless to where they are located to discuss the internship requirements, to determine and maintain the expected quality of practical experiences and to assess application of theory. For the purpose of this research project, the principal investigator scheduled a most convenient time for each participant to be interviewed using Skype communication toward the end of their second semester of the internship. Along with an interview schedule, each participant received, prior to his/her scheduled Skype interview, the following information to facilitate understanding regarding what would be discussed. Each was asked to review feedback for all completed assignments for the semester and prepare to discuss these topics in the Skype interview:

1. Discussion of perceived level of confidence in the preparation to be an educational leader;

2. Reflection on personal growth from Internship I to Internship II;

3. Discussion of clinical correlations assignments in comprehending to ISLLC standards;

4. Discussion of progress and significance of first major project and final major project (although may not be complete);

5. Overall impression of the educational leaders preparation program with a focus on the internship and using communications technology.

Following the completion of the Skype interview, the principal investigator administered a survey using Survey Monkey to determine the effectiveness of using Skype rather than face-to-face conferences. The questions to which participants responded are listed.

\section{Survey Questions}

1. Which best describes your skill level in using Skype?

2. Please describe your level of comfort in your supervisor's use of Skype to communicate the objectives and goals of the educational leadership internships.

3. Please assess your level of satisfaction regarding the internship experience, specifically as it relates to internship course design.

4. How likely are you to recommend the use of Skype or similar technology to communicate with your university supervisor instead of a face-to-face meeting?

5. Evaluate the importance of having a face-to-face internship conference with your university supervisor as opposed to using an online conference, e.g., Skype to the success of your internship.

6. Assess the degree to which you feel that your internship role was integrated into the school site.

7. To what degree do you feel that a vision for the internship was clearly developed?

8. To what degree were the goals for the internship communicated and emphasized? 
9. How would you rate the relevance of your internship activities to preparing you to be a school leader?

10. Did the reliability of Internet connections at your school site compromise your ability to communicate with your university supervisor or compromise your internship performance?

11. Did the use of an online conference, e.g., Skype, enhance, detract, or have no effect on your online relationship with your university supervisor?

12. Describe your honest assessment of face-to-face internship conferences relationships and use of online meetings for internship conferences.

Educational leadership students were required to enroll in two semesters of internship where teachers engaged in training and preparation for leadership roles in their schools or districts. The Skype interview was administered in the second semester of this internship. The coursework is mandated by the state as requirement to receive certification as an educational leader in Louisiana. Consequently, respondents were already enrolled in the course, negating the need to recruit.

At the ULM Educational Leadership program, there were three basic conditions that each prospective candidate met before beginning an internship preparation program for school leaders: (a) satisfying eligibility criteria; (b) completing application and acceptance procedures; and (c) ensuring appropriate placement. Eligibility requirement includes a minimum of three or five years of teaching experience if the applicant was seeking state certification, prior approval of a sponsoring administrator or site supervisor at the placement site or school site, completed application to the graduate school at ULM and its Educational Leadership program, and finally, the applicant must have completed $80 \%$ of the courses required for certification. To receive credit and graduate from the ULM program, students must score 166 or better on the SLLA examination to qualify for certification in the state of Louisiana.

\section{Sample}

Educational leadership students must enroll in two semesters of internship which prepares teachers for leadership roles in their schools or districts. The coursework is mandated by the state as a requirement to receive certification as an educational leader in Louisiana. Although interns had to take the internship course as part of their degree plan, they were not obligated to participate in this research study. Since interns were not obligated or required to participate in the study, the sample was inherently small $(N=9)$ in relation to the number of students taking the course during the fall or spring semester. It must be noted that the intern population included only students assigned to the principal investigator for this study to supervise. Normally, a supervisor is assigned the same students for both semesters of internship. This approach allowed for a professional relationship with the interns and provided uniformity in expectations. At least five additional students opted to participate and respond to the survey yielding 14 respondents.

\section{Results}

The respondents in the sample were surveyed from Fall Semester 2013 to Spring Semester 2014 which represents both halves of their year of internship. As the university supervisor in the first half of the internship, the principal investigator visited each intern and site supervisor at the school site to plan and discuss expectations. In the second half of the internship, only electronic communication was used to plan, discuss expectations, and determine strengths, weaknesses, and lessons learned. A Skype interview with each participant was a penultimate activity to taking a survey to determine and evaluate student growth and success. Fourteen intern respondents 
volunteered to take a 12-question survey. Results from the survey were reported using the categories of: (a) educational leadership program integrity; and (b) communications technology integration.

\section{Educational Leadership Program Integrity}

When asked to assess the level of satisfaction regarding the internship experience, specifically as it relates to internship course design, the respondents were evenly split between feeling adequately satisfied and quite satisfied. None of the respondents reported that they were dissatisfied. In fact, 13 out of 14 respondents overwhelmingly recommended the use of Skype or similar technology to communicate with their university supervisor instead of a face-to-face meeting. The respondents were requested to evaluate the importance of having a face-to-face internship conference with their university supervisor as opposed to using an online conference to the success of their internship. Nearly $43 \%$ indicated that face-to-face conferences were not important in their view; while nearly $43 \%$ reported that face-to-face internship conferences were somewhat important and just over $14 \%$ viewed that face-to-face conferences were most important. In assessing the degree to which they felt their internship role was integrated into the school site, $71.43 \%$ reported complete integration and $28.57 \%$ reported moderate integration. None of the respondents reported that there was no integration. Survey results indicated that just over $64 \%$ of the respondents and nearly $36 \%$ of the respondents sensed a clear vision of the internship was either adequately developed or highly developed respectively. Related to the vision, over $57 \%$ of the respondents reported that goals of the internship were communicated and emphasized with nearly $36 \%$ reported average degree of communication and emphasis. Only one (7.14\%) respondent felt that the goals for the internship were not communicated and emphasized at all. To determine the respondents' sense of relevance in internship activities to prepare for them to be a school leader, nearly $79 \%$ reported the activities to be highly relevant while $21.43 \%$ reported average relevance. None of the respondents reported that they sensed no relevance.

\section{Communications Technology Integration}

When asked to describe their skill level using Skype, just over 57\% reported their skill level as beginner, and just over $42 \%$ felt that they were somewhat skilled or experienced in the use of Skype. The respondents were asked to describe their level of comfort in their supervisor's use of Skype to communicate the objectives and goals of the educational leadership internships. Of the respondents, only two (14.29\%) did not feel comfortable while $85.72 \%$ reported their level of comfort either somewhat comfortable or quite comfortable. The authors were concerned about Internet accessibility and reliability, so the respondents were asked whether reliability of Internet connections at their school site compromised their ability to communicate with their university supervisor or compromised their internship performance. Over $85 \%$ of the respondents reported that neither communication nor performance was compromised. Additionally, $14.29 \%$ of the respondents reported compromise in only one area. When asked whether the use of an online conference, such as Skype, enhanced, detracted, or had no effect on their online relationship with the university supervisor, seven respondents (50\%) stated that the relationship was enhanced, while six (42.86\%) submitted that the online conference had no effect. Only one participant felt that this approach detracted from the relationship with the supervisor. The participants responded to one open-ended question from the survey. They were invited to describe their assessment of face-to-face internship conference relationships and use of online meetings for internship conferences. Thirteen of the 14 respondents opted to submit their assessment. To maintain the integrity of the responses, the study reported verbatim the open-ended submissions. It should be noted that references to "professor" and "instructor" 
represented the role of university supervisor. The following are directly quoted from participants who responded to the open-ended question. As direct quotations from the participants, statements and structure of sentences were not edited for grammar.

Skype, similar media, or in person were equally effective to me. Scheduling was much easier with Internet. (Student 2)

A face-to-face conference is nice because you can meet someone and get a good feel for their personality and demeanor. However, the Skype conference was extremely convenient for both the professor and me. Time is too valuable to waste driving two or more hours to visit one candidate for 30 minutes or so. I think the use of Skype models the concept of instructional technology at the administrative level. The process and setup offered zero problems or inconveniences. (Student 3)

I think online conferences with university supervisors is adequate for this course. (Student 4)

Since my internship site was further away than most. I feel as if a face-to-face meeting was not necessary for my university supervisor to spend the time to travel so far to meet with me since there are so many great pieces of technology, like Skype that can be used. I feel like my Skype meeting was just as effective as my Fall face-to-face meeting. (Student 5)

After I gain sufficient training in Skype, I would most likely choose conferences online for convenience. Another benefit of online conferences is the frequency of communication. Sometimes emails don't explain in layman's terms what is meant. (Student 7)

I found it very helpful to have face-to-face contact with my professor. It made me feel more personally connected to him. (Student 8)

I like the Skype. It saves time and gas for the professors. I got what I needed from the meeting. I just wish things such as my projects and exercises were explained earlier to me rather than after all things were complete and the semester was almost over. Earlier meetings like in February or March would be better. (Student 9)

I feel the online conference through Skype was a wonderful substitute instead of the face-to-face. We were able to conduct my Skype conference after school hours and any questions or concerns were answered by the supervisor through our Skype conference. This a good tool to use and hope the university will continue to use it. (Student 11)

I believe that is extremely important to be able to have a personal conference with your instructor. However, I think using Skype was just as good as a face-to-face meeting, because you are face-to-face. It was convenient for me and I am sure it was for our instructor. (Student 6)

\section{Discussion}

The initial thrust of this study was to highlight two research questions: 1 . Is there a difference between how educational leadership interns perceived their level of performance and preparation when the supervisor made an on-site visit and when the supervisor used communications technology in lieu of an on-site visit? and 2. Is there a difference between how educational leadership interns perceived support from the university supervisor when the supervisor made an on-site visit and when the supervisor used communications technology in lieu of the on-site visit? Data collected from the surveys showed that interns perceived overwhelmingly that level of performance and preparation were enhanced by use of communications technology and that little or no difference was perceived between a semester where an on-site visit was performed and using communications technology in lieu of the on-site visit during the second semester. Data collected indicated that interns encountered satisfaction with the support they received from their supervisor both during on-site visits and when communications technology was used in lieu of an on-site visit. With a small sample of these results, money was saved in the second semester for travel alone. Depending upon the distances traveled and current gas prices, this university supervisor typically spends from $\$ 350.00$ to $\$ 475.00$ on gas alone. Other university supervisors also expected to spend as much if they traveled outside of the parish. One respondent mentioned the importance of having a face-to-face conference with a supervisor, but added that "using Skype was just as good". 


\section{Conclusion}

Conclusions drawn from this small study seem to indicate that interns can feel supported in their internship experience when the quality of the experience was preserved regardless to whether they receive guidance electronically or via a face-to-face visit. The reported level of satisfaction with their performance, guidance, and rich interaction with their supervisor were important as substantiated by respondents in the survey, particularly with responses to the open-ended questions. The cost savings to travel is significant to all college educational leadership programs utilizing on-site visits. With ever decreasing funding from state education agencies for university supervisor travel, using some form of communications technology seems wise. Further study is warranted, however, to determine whether reporting results of this study would be replicated with a much larger sample of interns. For the study, it was possible to recruit only a small sample of convenience given the participants who were already interns in our Educational Leadership program. The authors acknowledge that the sample size does not nearly approach standards of generalizability in terms of how other interns might feel about their performance and preparation when using communications technology in lieu of face-to-face on-site visits.

Following the careers of these interns as they secure leadership roles and evaluating their effectiveness in their respective positions and schools may indicate the quality of their training and preparation. Preserving program integrity and maintaining performance expectations will translate to effective educational leadership. The authors believe that regardless to whether interns receive on-site visits or using communications technology, interns expect and desire close interaction with and regular access to both their site supervisor and university supervisor when appropriate or requested.

\section{Limitations}

Several limitations were inherent in the study. Due to the typical enrollment of the internship course sections, which only included interns who signed consent to participate in the study, the sample size was small. Consequently, the sample size was too small to support any claims to valid, general conclusions, and thus, this limitation is a potential impact on the findings. Still, another limitation that may have had a potential impact was that the data collected were self-reported by interns who may have felt that how they responded to the survey questions and Skype interview could affect their grade or the perception of their performance by their university supervisor. Interns were informed, however, in writing that their responses to the survey and Skype interview could not have any impact on evaluation of their performance in the internship. The authors suggest that if this study were replicated, the sampling size should include several sections of internship classes whether supervised by one university supervisor or several within the leadership preparation program. One final limitation was the variability in the familiarity of Skype which was not anticipated. Skype is widely used; therefore, it was presumed that participants would have no reservations relative to its use. Any frustration reported or not reported might affect responses to the survey. Although most educators are familiar with current technology use in classrooms, some guidance might be helpful if this study is replicated or if using Skype technology is proposed for internship visits.

\section{References}

Adams, L. (2011). Using Skype in clinical education. Radiologic Technology, 82(5), 475-477.

Bambrick-Santoyo, P. (2013). Good coaching leads to good leadership. Phi Delta Kappan, 94, 70-71. 
Cordeiro, P. A., \& Cunningham, W. G. (2013). Educational leadership: A bridge to improved practice. Upper Saddle River, N.J.: Pearson Education, Inc..

Cung, K. A., \& Miskel, C. (1989). A comparative study of principals' administrative behavior. Journal of Educational Administration, 27, 45-57.

Debruyn, R. L. (1997). Proactive leadership in the 21st century. Manhattan, K.S.: The Master Teacher.

Green, R. L. (2013). Practicing the art of leadership: A problem-based approach to implementing the ISLLC standards. Upper Saddle River, N.J.: Pearson Education, Inc..

Hersey, P., \& Blanchard, K. (1982). Management of organizational behavior: Utilizing human resources. Englewood Cliffs, N.J.: Prentice-Hall, Inc..

Hoy, H. W., \& Hoy, W. K. (2013). Instructional leadership: A research-based guide to learning in schools. Upper Saddle River, N.J.: Pearson Education, Inc..

Hoy, W. K., \& Miskel, C. G. (2013). Educational administration: Theory, research, and practice (9th ed.). New York, N.Y.: McGraw-Hill.

Implementing and Assessing Internships. (2002). ASHE-ERIC Higher Education Report, 29(3), 65-75.

Mayer, D. (2002). An electronic lifeline: Information and communication technologies in a teacher education internship. Asia-Pacific Journal of Teacher Education, 2(30), 181-189. Retrieved from http://www.merriam-webster.com/dictionary/ videoconferencing

Northhouse, P. G. (2013). Leadership: Theory and practice. Thousand Oaks, C.A.: Sage Publication, Inc..

Orr, M. T. (2011). Evaluating leadership preparation: Raising the stakes on accountability and lowering the boom on performance. Learning and Teaching in Educational Leadership, 1(19), 1-9.

Panos, P. T. (2005). A model for using video conferencing technology to support international social work field practicum students. International Social Work, 48(6), 834-841.

Parker, J., Boase-Jelinek, D., \& Herrington, J. (2011, October 18-21). Perceptions and reflections: Using Skype chat to build a community of learners. Paper presented at The E-LEARN 2011-World Conference on E-learning in Corporate, Government, Healthcare \& Higher Education, Honolulu, Hawaii, USA.

Quillen, I. (2011). Educators move beyond the hype over Skype. Retrieved January 5, 2015, from http://www.edweek.org/dd/ articles/2011/02/09/02skype.h04.html

Siccone, F. (2012). Essential skills for effective school leadership. Upper Saddle River, N.J.: Pearson Education, Inc..

Skype. (2013). In Oxford Dictionaries.com. Retrieved April 12, 2013, from http://oxforddictionaries.com/us/definition/american _english/Skype 